\title{
El Séptimo Arte en la publicidad insertada en las revistas editadas en Portugal (1999-2009)
}

Aida María de Vicente Domínguez | amdevicente@gmail.com

Investigador posdoctoral

CIAC- UNIVERSIDADE DO ALGARVE

Resumen: El presente estudio pretende dar a conocer cómo los creativos usan el Séptimo Arte para anunciar productos o promocionar marcas. Describir estrategias utilizadas por los publicitarios apoyándose en el cine, identificar cuál de ellas es la más representativa y conocer qué sectores económicos se anuncian a través de este recurso son los objetivos de la investigación. La metodología ha consistido en analizar la totalidad de la publicidad insertada a lo largo de diez años (1999-2009) en la revista semanal de información general nacional e internacional más leída en Portugal, Visão, que incluya referencias o elementos procedentes de la industria cinematográfica.

Palabras clave: cine, publicidad, estrategias publicitarias, creatividad.

Abstract: This research study intends to show how advertisers use the Seventh Art to promote different products or brands. Describing strategies that are used by publicists based on cinema, identifying which is the most representative one, and which economic sectors are announced though this resource, are the goals for this research project. Methodology consisted on analyzing the totality of advertizing that has been inserted in the most read national and international information weekly magazine in Portugal (Visão) for ten years (1999-2009) that includes references or elements from the cinema industry.

Key words: cinema, publicity, advertising strategies, creativity. 


\section{Introducción}

La conexión con el receptor es una de las grandes prioridades de la publicidad. Los publicitarios intentan crear anuncios que impacten, cautiven, convenzan, motiven e induzcan al acto de compra. Y para conseguir estos fines centran todos sus esfuerzos en su estrategia creativa utilizando un ingente repertorio de procedimientos "poniendo en juego toda clase de recursos persuasivos" (Hernández, 1998: 239).

En concreto, el presente estudio pretende investigar una estrategia específica: el cine como recurso creativo en la publicidad. Un campo de estudio que ha sido abordado por diversos investigadores. Significativas son las aportaciones ofrecidas por Covaleski (2003) y Laurindo y García (2009) sobre los interfaces comunicacionales en anuncios de televisisón con referencias cinematográficas.

Así como, relevantes son los estudios que han aborbado estas transferencias en el sector automovilístico: De Oliveira (2004) trató las confluencias existentes entre el film "Cidade de Deus", de Fernando Meirelles, y el spot "Beat the Devil" de la marca de coches BMW. Jover (2008) mostró las influencias del medio cinematográfico en este sector. García Bénitez y Jiménez Marín (2011) identificaron la intertextualidad existente entre el spot "Cinco años" del coche Mercedes Clase C con la película "Big". Y Jiménez Marín y Elías (2013) evidenciaron los nexos existentes entre algunas campañas de la marca de automóviles Volkswagën y la saga dirigida por George Lucas "Star Wars".

El uso de los géneros cinematográficos como estragegia de comunicación publicitaria es otro de los interfaces analizados. Rocha, Araldi y Bona (2011) mostraron cómo la idea creativa para elaborar el breifting de cuatro anuncios de la marca Eloeth se basó en elegir exclusivamente films musicales.

Y destacables son las investigaciones centradas en analizar la publicidad producida por cineastas. Oliveira (2011) efectuó un anàlisis comparativo entre los spots creados por el realizador portugues Marco Martins y algunas secuencias de sus películas. Azevedo (2011) abordó el cortometraje Chanel no 5 conducido por Baz Luhrmann (2004) en el que Nicole Kidman se encuentra en la escena con Rodrigo Santoro, y el comercial Gucci Guilty al frente de Frank Miller (2010) con Rachel Wood y Chris Evans. Con posterioridad, Miguel y Martín Casado (2014) también centraron su campo de estudio en el spot del perfume Chanel no 5 cuya campaña fue protagonizada por Nicole Kidman.

Unas investigaciones que tratan esta interrelación principalmente en los anuncios emitidos por televisión. Por ello, este estudio se centra en la publicidad gràfica: ampliando el análisis a todos los sectores, investigando nuevas variables y centrando la investigación en un área geográfica específica, Portugal. 
En concreto, se analiza la presencia del cine en la publicidad gráfica insertada en las revistas de información general nacional e internacional editadas en Portugal: ¿Cómo utilizan los creativos o publicitarios el Séptimo Arte para anunciar productos? ¿Qué objetos de consumo se anuncian con referentes cinematográficos? ¿Cuáles son las estrategias apoyadas en el cine más representativas?, son las cuestiones que se pretenden investigar. Por tanto, los objetivos del estudio son:

> Averiguar qué sectores económicos suelen anunciarse más asiduamente con referentes cinematográficos.

$>$ Identificar estrategias publicitarias apoyadas en el cine.

> Conocer cuáles son las estrategias apoyadas en el Séptimo Arte más representativas.

Una investigación que pretende mostrar cómo usan los creativos del Séptimo Arte para anunciar productos o promocionar marcas y qué les interesa de la historia del cine para transferirlo a la publicidad impresa.

\section{Metodología}

La metodología empleada para el estudio se ha estructurado en los siguientes pasos:

> Búsqueda bibliográfica en diversas bases de datos (Dialnet, DOAJ, EBSCO, Teseo), catálogos (Rebiun, WorldCat) y motores de búsqueda (Buscopio, MetaCrawler, Scirus), para conocer las perspectivas analizadas en estudios precedentes y la viabilidad del tema a investigar.

> Selección del medio: la revista seleccionada es Visão, revista de información general nacional e internacional más leída en Portugal durante 2013, según los datos aportadas por APCT (Associação portuguesa para o control de Tiragem e Circulação). La homogeneidad de la selección se justifica porque la publicidad que se inserta en esta revista no es exclusiva del medio pues las marcas también pagan por publicitar el mismo anuncio en otros soportes impresos.

> Análisis total y no aleatorio de las revistas que componen la muestra: se opta por visionar la publicidad insertada en los 480 ejemplares publicados desde enero de 1999 a diciembre de 2009.

> Publicidad analizada: se seleccionan aquellos anuncios que insertan el Séptimo Arte como recurso creativo para anunciar productos independientes de la industria cinematográfica.

> Elaboración de una base de datos en un documento Excel: de cada anuncio se indica año, producto, marca, sector económico y estrategia utilizada. Para analizar los 
sectores económicos se opta por usar la clasificación aportada por Infoadex. Y para analizar las estrategias publicitarias la analista, tras visionar las diversas variantes y aportar una denominación a cada categoría, computa la representatividad de dichas estrategias y realiza una correlación con los sectores económicos.

$>$ Volcado de los contenidos de la tabla Excel al programa SPSS para investigar dos variables: principales estrategias publicitarias apoyadas en el cine y sectores económicos.

$>$ Exposición e interpretación de los resultados y conclusiones de la investigación.

\section{Resultados}

\subsection{Sectores económicos: productos}

Uno de los objetivos de la investigación es identificar los principales sectores económicos que se anuncian con esta estrategia publicitaria. Los resultados obtenidos pueden visualizarse en la tabla 1:

Los sectores representados son por orden decreciente: "Objetos personales" (28,1\%), "Textil y Vestimenta" (11,7\%), "Automoción" (10,7\%), "Belleza e Higiene" (8,7\%), "Hogar" (8,7\%), "Cultura, Enseñanza y Medios de Comunicación" (7,7\%), "Telecomunicaciones e Internet" (6,8\%), "Alimentación" (4,9\%), "Finanzas" (4,9\%), "Distribución y Restauración" (3,9\%) "Equipos de Oficina/Electrónica/Informàtica y Comercio" (2,9\%), y "Salud" (1\%).

Por tanto, este recurso tiende a usarse con mayor frecuencia para anunciar "Objetos personales" y en un segundo orden para publicitar "Textil y Vestimenta" y "Automoción". Pero cada uno de estos sectores engloba una amplia variedad de productos. Por ello, se ha considerado ahondar en la investigación para conocer qué objetos de consumo de los sectores más representativos suelen anunciarse con esta técnica publicitaria. Y los resultados indican los siguientes datos:

$\checkmark$ El 99\% de los anuncios agrupados en "Objetos personales" anuncia productos vinculados con "Relojería y joyería" y un $1 \%$ con "Óptica".

$\checkmark$ El 100\% de los anuncios que se engloban en "Automoción" se clasifican dentro una misma categoría: "Automóviles de turismo".

$\checkmark \quad$ En "Textil y Vestimenta" todos los productos pertenecen a "Confección exterior".

Esto indica que los creativos o publicitarios recurren al Séptimo Arte para anunciar principalmente productos que reflejan la identidad, el estatus, los valores y gustos personales del consumidor en la esfera social. 
Asimismo, se considera relevante destacar que la publicidad de otros sectores también se caracteriza por cierta homogenidad en el producto anunciado a través del Séptimo Arte:

$>$ Todos los productos que pertenecen al sector "Hogar" pertenecen a la categoría "Sonido y televisión". El 100\% de "Cultura, Enseñanza y Medios de Comunicación" a "Medios de comunicación". La totalidad de "Distribución y Restauración" a "Grandes superficies". El 100\% de "Equipos de oficina/Electrónica/ Informática y Comercio" a "Informática". Y el único anuncio del sector "Salud" se engloba en "Medicamentos".

Por tanto, parece existir una inclinación de los publicitarios por usar el cine como recurso para anunciar productos específicos de cada sector económico.

\subsection{Estrategias publicitarias apoyadas en el Séptimo Arte}

El segundo objetivo de la investigación es identificar estrategias publicitarias usadas por los creativos para anunciar productos o promocionar marcas apoyándose en el Séptimo Arte. Y los resultados obtenidos en la muestra objeto de estudio $(n=103)$ desvelan diez modalidades o recursos creativos:

$>$ Interpretes cinematográficos: consiste en recurrir a actores y actrices para anunciar productos (Harryson Ford anuncia el automóvil Lancia Lybra, Penélope Cruz el Honda Jazz y Catherine Zeta Jones el Alfa Sportwagon) o promocionar marcas (George Clooney, en la muestra analizada, promociona Emidio Tucci y Nespresso).

> Cartelera: modalidad caracterizada por recurrir a los carteles cinematográficos. En concreto, la muestra desvela dos variantes. Anunciar un producto a través del cartel de una película que está o estuvo en cartelera (la marca Tissot anuncia uno de sus relojes insertándolo dentro del cartel de la película "Lara Croft: Tomb Raider", dirigida por Simon West), o bien, crear un cartel cinematográfico ficticio, exclusivamente, para anunciar un producto (el banco comercial portugues NovaRede publicita su crédito habitacao de mensualidad fija a través de un cartel cinematográfico ficticio en la parte superior compuesto por la imagen del rostro de un hombre agobiado, junto al texto: "La horripilante historia das taxas que nao paravam de subir $[\ldots]$ ". Debajo del cartel se argumenta: "Se está farto deste filme, reja como pagar sempre a mesma prestacao mensal $[\ldots]^{\prime \prime}$.

$>$ Directores fílmicos: directores de cine que forman parte de la escena publicitaria. Generalmente, han sido galardonados por la industria cinematográfica. La marca Swatch creó en Portugal un reloj de edición limitada basado en el director portugués Manoel de Oliveira y en su publicidad gràfica opta por insertar el producto junto al texto: "Un Swatch com a assinatura de Manoel de Oliveira". 
> Caràtula de DVD: técnica publicitaria que consiste en promocionar una marca o anunciar un producto junto a la cáratula del DVD de una a varias películas que han estado en cartelera. Revistas portuguesas como Visão, o periódicos editados en Portugal como Expresso se anuncian junto a carátulas de DVD indicando que esas películas se regalan con la compra del ejemplar en fechas concretas.

$>$ Herramientas de rodaje: recurso creativo que consiste en utilizar las herramientas que se utilizan en un rodaje cinematográfico (claquetas, celuloides, etc). Las galletas de chocolate de la marca Filipinos se anuncian con una claqueta que inserta "A rodar!", junto al texto: "Tu fazes os anuncios, nós os Filipinos! Informáte em: www.filipinos.com".

> Fotogramas: modalidad caracterizada por utilizar uno o varios fotogramas de una película, o bien, crear fotogramas ficticios. Samsung, anuncia su teléfono móvil SGHV200 y el televisor TFT-LCD con fotogramas de la película "The Matrix Reloaded" en las pantallas de dichos productos.

$>$ Objetos de cine: estrategia basada en recurrir a objetos usados en las películas por los personajes protagonistas. El centro comercial portugués Colombo utilizó como recurso visual el coche volador usado por Harry Potter junto al el texto " O carro de Harry Potter está no Colombo", para informar que en sus indagacions se exhibía una exposición de coches usados en películas.

$>$ Personajes de cine: técnica publicitaria que consiste en seleccionar a personajes de películas para que formen parte de la escena publicitaria. Para anunciar los chicles Trident advantage se utiliza como impacto visual una versión del personaje interpretado por Rita Hayworth en la película "Gilda" , dirigida por Charles Vidor, en la mítica escena donde escenifica la canción "Put the blame om mame" mientras se despoja sensualmente de un guante.

> Salas de cine: el creativo anuncia un producto usando como técnica creativa los espacios acondicionados para la proyección de películas cinematográficas, las salas de cine (LG anuncia el ordenador LW60 Express Notebook sustituyendo la pantalla de una sala de cine por la del producto anunciado). O bien, hacen uso de las sensaciones percibidas durante el visionado de un film en una sala de cine (Pionerr publicita el portatil PDV-LC10 con la imagen de una chica emocionada junto al texto: "Será que levamos o cinema en casa Longe demais?").

> Títulos fílmicos: modalidad caracterizada por adaptar el título de una película basada en una novela al producto anunciado, estrategia aportada anteriormente por Escribano (2003). Vodafone publicita durante un periodo determinado que aquellos clientes que tengan la tarifa Yorn en Portugal, al adquirir una entrada de cine se les 
obsequiará con otra, y para ello, en su publicidad gràfica adapta el título de la película "El Señor de los Anillos" al producto anunciado, "O Senhor dos Bilhetes".

Por tanto, los datos indican que son diversas las transferencias de la industria cinematogràfica a la publicidad gràfica con el objeto de llegar al espectador. $Y$ es que los creativos recurren tanto a los directores de cine como a los actores o actrices, a las herramientas usadas en los rodajes y al lugar de proyección o exhibición de las películas: las salas de cine. Así como, a elementos específicos de un film: personajes protagonistas y objetos usados por éstos, fotogramas, e incluso a los títulos fílmicos y a la cartelera cinematográfica.

Unas estrategias que utilizan, quizás, por algunos de los siguientes motivos:

$\checkmark \quad$ La marca ha invertido en el patrocinio de una película.

$\checkmark \quad$ El producto se ha usado en una producción cinematogràfica.

$\checkmark \quad$ La marca ha organizado eventos vinculados con el cine.

$\checkmark$ La marca ha creado un producto exclusivo de edición limitada con un referente cinematográfico específico.

$\checkmark$ Porque un determinado producto regala un obsequio vinculado con la industria cinematogràfica.

$\checkmark \quad$ O simplemente porque el creativo decide usar el cine como recurso creativo en la publicidad impresa sin que ese producto o marca tenga, a priori, ninguna vinculación especial con la industria cinematográfica que determine la estrategia publicitaria.

\subsubsection{Manifestación artística más representativa}

Analizados los sectores económicos más representativos que se anuncian en la muestra objeto de estudio y expuestas las modalidades halladas, el siguiente objetivo del estudio es dar respuesta a la cuestión ¿Cuáles son las estrategias apoyadas en el cine más representativas? Y los resultados obtenidos pueden observarse en la tabla 2:

Los datos indican que las técnicas más frecuentes son "Intérpretes cinematográficos" $(47,6 \%)$ y en un segundo orden "Personajes de cine" $(15,5 \%)$. Así como, significativas son las características que presentan cada una de estas estrategias:

$>$ Se recurre con mayor asiduidad a intérpretes que han sido galardonados por la industria cinematográfica. En menor grado a actores y actrices conocidos o premiados por su papel en determinadas series de televisión y que han interpretado algún papel en la gran pantalla. 
$>$ Los personajes de cine que aparecen en la muestra objeto de estudio son personajes protagonistas de películas que comparten uno o varios de los siguientes criterios: muy taquilleras, premiadas por la industria cinematogràfica, exitosas adaptaciones de cuentos populares y series de televisión, películas míticas de un género cinematográfico.

Recurrir a intérpretes cinematográficos probablemente se utilice para asociar las cualidades del actor o actriz al objeto anunciado para indicar que consume el producto. Así como, que sean actores y actrices conocidos aumenta la credibilidad entre el público y el posicionamiento de la marca.

El estudio realizado por la agencia alemana CPI Celebrity Performance Log sobre el uso de famosos en la publicidad concluye que "los anunciantes que cuentan con famosos para sus campañas, no sólo gozan de mayor credibilidad entre los consumidores, sino que también consiguen despertar mayor simpatía entre el público" (Son las campañas, 2013: Web).

Quizás por ello, también recurren a los personajes protagonistas de las películas: son facílmente reconocidos por el público permitiendo establecer de forma segura el reconocimiento por parte del espectador y un mayor posicionamiento de la marca.

Asimismo, significativas son las estrategias que ocupan un tercer orden: "Carátulas de DVD" (12,6\%), "Cartelera" y "Fotogramas" (ambas con un 5,8\%). Recurrir a carteles cinematográficos que han estado en cartelera o utilizar sus características, estructura o composición probablemente sea para lograr el gran impacto visual que éstos provocan en el público. Las carátulas de DVD probablemente se inserten como contenido publicitario porque muchas marcas para aumentar sus ventas determinan regalar películas que han estado en cartelera, como efecto motivador para la compra de un producto. Así como, se considera que los fotogramas se utilizan para retener el producto en la mente del consumidor a través de imágenes fílmicas que forman parte del colectivo social.

No obstante, para comprobar estos resultados se realiza la correlación sectores económicosmanifestación artística. Y los datos corroboran que las estrategias "Intérpretes cinematográficos" y "Personajes de cine" son las más usadas para anunciar determinados productos de sectores divergentes ( ambas superan el 60\% de representación), seguidas de "Carátulas de DVD" y "Cartelera" usadas por el 41\% y "Fotogramas" con una representación del $33,3 \%$.

\section{Conclusiones}

Las conclusiones obtenidas tras analizar la presencia del Séptimo Arte como recurso creativo en la publicidad gráfica de las revistas editadas en Portugal son las siguientes:

- Los sectores económicos que se anuncian más asiduamente con referentes cinematográficos son: "Objetos personales", "Textil y Vestimenta" y "Automoción". 
- Los creativos usan esta estrategia de comunicación para anunciar, generalmente, productos específicos pertenecientes a categorías concretas.

- Determinados productos suelen anunciarse con mayor frecuencia junto al Séptimo Arte. En concreto, suelen pertenecer a las siguientes categorías: "Automóviles de turismo", "Confección exterior", "Grandes Superficies", "Informática", "Medios de Comunicación", "Óptica, "Sonido y televisión", "Relojería y Joyería".

- Las estrategias usadas por los creativos apoyadas en el cine son diversas y variadas. En concreto, se han identificado diez modalidades. Los publicitarios recurren a: "Directores fílmicos", "Cartelera", "Fotogramas", "Intérpretes cinematográficos" (actores y actrices), "Personajes de cine", "Objetos de cine", "Títulos fílmicos", "Herramientas de rodaje" (claquetas, celuloides, etc), "Carátulas de DVD", y al lugar de proyección o exhibición de las películas, las salas de cine.

- Las estrategias apoyadas en el cine que se usan con más frecuencia en la publicidad son dos: "Intérpretes cinematográficos" y "Personajes de cine".

- Cuando recurren a "Intérpretes cinematográficos", suelen elegir entre quienes han sido nominados o galardonados por la industria cinematográfica. Y en menor grado recurren a intérpretes cinematográficos conocidos o premiados por su papel en determinadas series de televisión y que han interpretado algún papel en la gran pantalla.

- Cuando usan "Personajes de cine" éstos suelen ser los protagonistas de películas que generalmente reunen uno o varios de los siguientes criterios: muy taquilleras, premiadas por la industria cinematográfica, exitosas adaptaciones de cuentos populares o series de televisión, películas míticas de un género cinematográfico.

- Líneas de investigación futuras pueden profundizar en esta perspectiva de estudio, aportando nuevas estrategias publicitarias apoyadas en el cine, o analizando especificamente una tàctica publicitaria.

\section{REFERENCIAS BIBLIOGRÁFICAS}

AZEBEDO, Denise (2011): "Estratégias estéticas em comerciais de perfumes dirigidos por cineastas", en Comunicação Midiática, vol. 6, no 3, pp. 71-90.

COVALESKY, Rogério (2003): Cinema e publicidade televisual: Interfaces comunicacionais. Universidad de Tuiuti do Paraná. Brasil, en http://tede.utp.br/tde_busca/arquivo.php?codArquivo=19 (consultado: 20/01/2014).

ESCRIBANO, Asunción (2010): "Literatura, Cine y Publicidad". En Espéculo, no 46, en http://pendientedemigracion.ucm.es/info/especulo/numero46/litpubl.html (consultado: 02/02/ 2014). 
DE OLIVEIRA, Annelore (2004): Cinema e publicidade: dois campos em ação - um estudo sobre as confluências dos campos cinematográfico e publicitário, en http://www.lume.ufrgs.br/handle/10183/73975 (consultado: 20/01/2014).

GARCÍA BENÍTEZ, María del Carmen; JIMENEZ MARÍN, Gloria (2011): "Cine y publicidad. La intertextualidad en el anuncio de Mercedes Clase C", en Comunicación: revista Internacional de Comunicación Audiovisual, Publicidad y Estudios Culturales, no 9, pp. 82-92.

HERNÁNDEZ MARTÍNEZ, Caridad (1998): "Creatividad publicitaria y contexto social", en ZER, no 4, pp. 239-263.

JIMÉNEZ MARÍN, Gloria; ELÍAS, Rodrigo (2013): "Cine y publicidad. La intertextualidad en las campañas de Volkswagen", en Arte, Individuo y Sociedad, vol. 25, no 1, pp. 153167.

JOVER, Rafael (2007): "El cine en la publicidad de automóviles", en Perales, F: Cine y publicidad. Madrid: Fragua, pp. 99- 121.

LAURINDO, Roseméri; MARREIRO, Tharcyla (2009): "A intertextualidade cinematográfica em comerciais de televisão", en Conexão - Comunicação e Cultura ,UCS, Caixas do Sul, vol.
8 ,
$\mathrm{n}^{\circ}$
15 ,
en

http://www.ucs.br/etc/revistas/index.php/conexao/article/viewFile/121/112 (consultado: 20/01/2014).

MEIER, Annemarie (2010): "Cine y spot publicitario", en El ojo que piensa (revista de cine iberoamericano) $\mathrm{n}^{0}$ 1 , en http://www.elojoquepiensa.net/elojoquepiensa/index.php/numeros-anteriores (consultado: 20/01/2014).

MIGUEL, Mercedes; MARTÍN CASADO, Teresa Gema (2014): "Los referentes cinematográficos en la creatividad publicitaria (spot de Chanel n5 en su campaña con Nicole Kidman)", en Liberal, S., y Piedad Fernández Perea, P: Últimos estudios en publicidad: de "Las Meninas" a los Tuits. Madrid: Fragua, pp. 217-234.

OLIVEIRA, Ricardo João (2011): Cinema e publicidade, implicações criativas e financieras. Universidad de Minho, Braga en http://repositorium.sdum.uminho.pt/handle/1822/16082 (consultado: 25/01/2014).

ROCHA, Marcelle; ARALDI, Marina Vivian; BONA, Rafael Jose (2011): A Influência do Cinema na Criação em Publicidade Propaganda: a Intertextualidade na Comunicação Publicitária da Marca Eloet. Intercom - Sociedade Brasileira de Estudos Interdisciplinares da Comunicação. XIII Congresso de Ciências da Comunicação na Região Nordeste - Maceió - AL - 15 a 17 de junho de 2011, en 
http://intercom.org.br/papers/regionais/nordeste2011/resumos/R28-0356-1.pdf (consultado: 20/02/2014).

"¿Son las campañas protagonizadas por famosos mas efectivas? Un estudio tiene la respuesta" (2013), en Marketing directo, en http://www.marketingdirecto.com/actualidad/publicidad/son-las-campanasprotagonizadas-por-famosos-mas-efectivas-un-estudio-tiene-la-respuesta/ (consultado: 01/ 03/ 2014).

[Recibido: 15 de septiembre de 2014. Aceptado con cambios: 2 de febrero de 2016. Aceptado: 12 de febrero de 2016] 